\title{
Chlamydia pneumoniae Infection in Children with Lower Respiratory Tract Infections
}

\author{
SHUJI YAMADA \\ Department of Pediatrics and Child Health, Kurume University School \\ of Medicine, Kurume 830, Japan
}

Received for publication April 3, 1995

\begin{abstract}
Summary: The incidence of antibody and the clinical features of Chlamydia pneumoniae (C.pneumoniae) infection have not been studied in children in Japan. We investigated the incidence of C.pneumoniae antibody in sera from 580 healthy children (including 30 umbilical cord blood samples) during the 2-year period between June 1992 and June 1994. The antibody titer was determined by a microimmunofluorescence (MIF) test by using the elementary body of C.pneumoniae TW-183 as the antigen. Umbilical cord blood samples were positive for the antibody in $50 \%$ of newborns tested at birth. The incidence of positivity decreased to $0 \%$ in 1 year-old children. It was still low in children up to 5 years of age and then increased rapidly in children 6 years of age or older. The positivity reached $55 \%$ in 7-year-old children and remained at this level in children older than 7 years of age. High antibody titer (IgG 2512 ), indicating recent infection, was observed in $13(2.2 \%)$ of the 580 children, two of whom showed no symptoms. We detected the pathogen in throat swabs by culture and capillary polymerase chain reaction (PCR), and determined IgM and IgG serum titers to C.pneumoniae in 130 children with lower respiratory tract infection (91 with pneumonia and 39 with bronchitis) between December 1993 and December 1994. The infection due to C.pneumoniae was confirmed in 10 (7.7\%). Of these, 7 were boys and 3 were girls, ranging in age from 9 months to 12 years. The clinical manifestations of the infection were mild symptoms like in common cold; post-nasal discharge, hoarseness and prolonged cough were relatively characteristic. There was no significant difference in the incidence of serum positivity between the healthy children group and the patients group. The present study suggests that primary-schoolers show antibodies for C.pneumoniae with nearly the same frequency as adults. Mild clinical symptoms are very common in C.pneumoniae infections in children as in adults.
\end{abstract}

Key words: Chlamydia pneumoniae - children - respiratory tract infection - microimmunofluorescence test - capillary PCR

\section{Introduction}

Chlamydia pneumoniae (C.pneumo- niae), TWAR strain, the third species of Chlamydia, is a new microorganism reported by Grayston et al. (1989). The 
first isolates were TW-183 strain detected in the conjunctiva of a healthy child during a study of trachoma vaccine in Taiwan in 1965 (Grayston et al. 1986). However, the strain was not identified. Grayston et al. (1986) isolated the AR-39 strain from a student with pharyngitis at an outpatient clinic of Washington University in 1983. The biological features of this strain were the same as those of the TW-183 strain. Therefore, the TW-183 and AR-39 strains were unified as the TWAR strains. Since Marrie et al. (1987) and Grayston et al. (1989) reported these strains as important pathogens of pneumonia and bronchitis, they have attracted attention as a causative organism of respiratory infectious diseases. Subsequently, C.pneumoniae has come to be investigated in the Western countries. The incidence of communityacquired pneumonias in adults is believed to be $6-18 \%$ (Marrie et al. 1987; Chirgwin et al. 1991). However, such an investigation has rarely been performed in the pediatric field. Saikku et al. (1988), determining serum antibody titers in 220 children (under 5 years of age) with lower respiratory tract infection in the Philippines, reported that the incidence was $9.1 \%$. 6.4\% of the children, in whom a recent infection was suspected, showed a high antibody titer. In Japan, Kishimoto et al. (1990) found that the incidence increased rapidly in children 6 years of age or older and that the incidence in 15-year-old children was already similar to that in adults.

To clarify the incidence of C.pneumoniae infection in the present study, we assessed the antigen of $C$. pneumoniae by culture, capillary polymerase chain reaction (PCR), and IDEIA Chlamydia, and determined the serum antibody titers using a microimmunofluorescence (MIF) test in children with lower respiratory tract infections and in healthy children.

\section{Subjects and Methods}

\section{Subjects}

The subjects were 130 children (age 0-15 years) with lower respiratory tract infections (91 with pneumonia and 39 with bronchitis), who were brought to the Department of Pediatrics of Kurume University Hospital or to its affiliated hospitals between December 1993 and December 1994. The normal control group consisted of 550 healthy children in the same age range ( 260 boys and 290 girls), who were brought to the above-mentioned facilities during the 2-year period between June 1992 and June 1994. The umbilical cord blood samples from 30 pregnant women were used for determination of antibody titer at birth. Informed consent was obtained in all cases from parents or guardians.

\section{Methods}

Determination of serum antibody titers and diagnostic criteria: Collected sera $(0.5 \mathrm{ml})$ were stored at $-70^{\circ} \mathrm{C}$ before use. The MIF test, the indirect fluorescent antibody technique using the elementary body (EB) of Chlamydia species as an antigen, was used for the determination of Chlamydia serum antibody titers, and IgM and IgG antibody titers were determined (Wang et al. 1970). The antigens used were EBs of $\mathrm{L}_{2}$ strains of C. trachomatis (Washington Research Foundation, Seattle), budgerigar strains of C. psittaci (from Dr. Yasuo Kanamoto, Hiroshima Prefectural Institute of Public Health, Japan), and TW-183 strains of $C$. 
pneumoniae (Washington Research Foundation, Seattle). The antigens were mixed with an equal amount of $3 \%$ normal yolk sac suspension and placed with a pen point in the wells of a microslide glass for fluorescent detection (Matsunami, Japan). The slide was air-dried and fixed in acetone for $15 \mathrm{~min}$ at room temperature. Tested serum $(25 \mu \mathrm{l})$ was subjected to two-fold stepwise dilution with phosphate buffered saline (PBS, pH 7.4) (IATRON, Tokyo, Japan) and reacted with the antigens in wells at $37^{\circ} \mathrm{C}$ for $30 \mathrm{~min}$ in a moist chamber. After incubation, the slide was rinsed four times with PBS $(\mathrm{pH}$ 7.4) and twice with distilled water. After air-drying, the sample was reacted with fluorescein isothiocyanate (FITC)-labelled goat anti-human IgM/IgG (Cappel Inc., USA) and PBS (pH 7.4) containing 0.04\% Evans blue for counterstaining. The sample was reacted at $37{ }^{\circ} \mathrm{C}$ for $30 \mathrm{~min}$ in a moist chamber and air-dried after rinsing. The samples were observed with a fluorescent microscope (Nikon, Japan) at $400 \times$ after mounting in glycerol. The maximum dilution, at which the fluores- cence specific to EB could be observed, was defined as the antibody titer (Fig. 1). An IgG antibody titer of $\geq 32$ was regarded as positive for C.pneumoniae antibody. The diagnosis of recent $C$. pneumoniae infection was based on the following criteria (Grayston et al. 1989): (1) IgM antibody titer 216 , (2) a four-fold or greater titer change between paired sera, (3) IgG antibody titer $\geq 512$.

$P C R$ : The nasopharynx of patients was wiped with a Dacron swab (DAKO DIAGNOSTICS LTD., USA). The swab was stored in $1 \mathrm{ml}$ of transport medium containing a sucrose-phosphate-glutamate (SPG) buffer to avoid drying. The collected specimens were left to stand at $4{ }^{\circ} \mathrm{C}$ for $1-4 \mathrm{hs}$, then stored at $-70{ }^{\circ} \mathrm{C} .500$ $\mu \mathrm{l}$ of specimen was centrifuged at 15,000 rpm for $30 \mathrm{~min}$, and DNA was extracted from the sediment by means of IsoQuick ${ }^{\mathrm{TM}}$ (MICRO PROBE Co., USA). The primers used were CHP-1 and CHP-2, which amplify the 437-base pair (bp) within C. pneumoniae-specific 474-bp PstI restriction fragment reported by Campbell et al. (1992); CHP-1: GTTGTTCATGAAGGCCTACT,

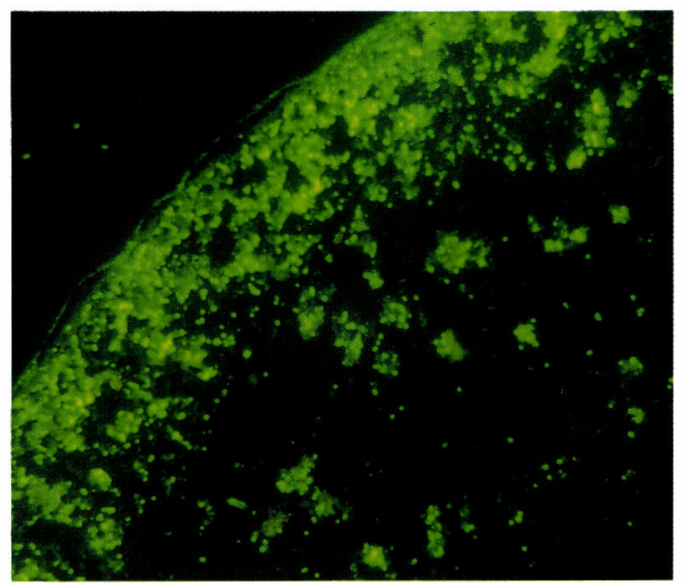

(A)

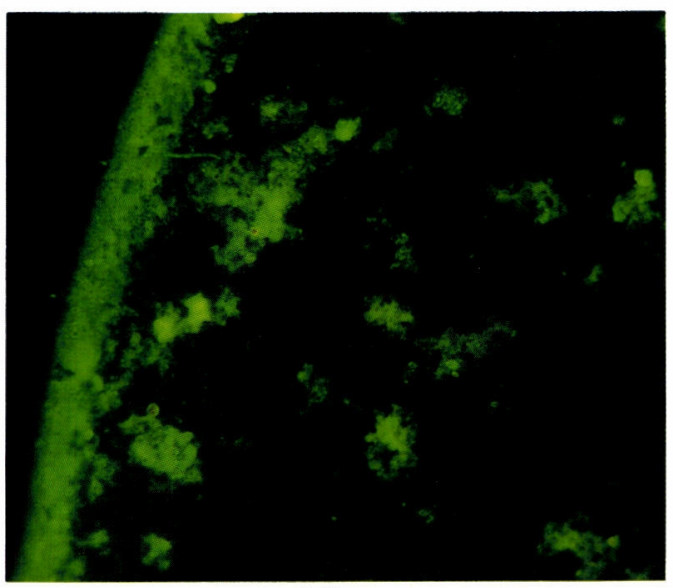

(B)

Fig. 1. Fluorescence microscopic findings by MIF test showing the results of antibodypositive (A) and negative (B). $(\times 400)$ 
CHP-2: TGCATAACCTACGGTGTGTT. The PCR solution was prepared with the method of Wittwer et al. (1991); $10 \mu \mathrm{l}$ of $10 \times$ buffer, $80 \mu$ l of distilled water, and $10 \mu l$ of $10 \times \mathrm{dNTP}$ were mixed to prepare the PCR buffer, and $15 \mu \mathrm{l}$ of the buffer was used. The capillary PCR Taq polymerase used was $1 \mu \mathrm{l}$ of a mixture of 1.5 $\mu \mathrm{l}$ of Taq polymerase (TAKARA, Japan) and $6 \mu \mathrm{l}$ of diluent buffer. The capillary primer used was prepared by mixing together $1 \mu \mathrm{l}$ of a mixture of CHP-1 $(5 \mu \mathrm{l})$ and distilled water $(15 \mu \mathrm{l})$ with $1 \mu \mathrm{l}$ of a mixture of CHP-2 $(5 \mu \mathrm{l})$ and distilled water $(12.5 \mu \mathrm{l}) .2 \mu \mathrm{l}$ of sample was added to the capillary primer to a volume of $20 \mu \mathrm{l}$. The reaction solution was transferred to a glass capillary tube (Idaho-Technology Inc., USA), and the following reactions were carried out by capillary PCR amplifier (Idaho-Technology Inc., USA): (1) denaturation, $94^{\circ} \mathrm{C}$ for $3 \mathrm{sec}$; (2) annealing, $55^{\circ} \mathrm{C}$ for $1 \mathrm{sec}$; (3) extension, $75{ }^{\circ} \mathrm{C}$ for $15 \mathrm{sec}$. The reactions (1) through (3) were regarded as one cycle, and 50 cycles were carried out. The PCR prod-

$\begin{array}{llllllllll}M & P & N & 1 & 2 & 3 & 4 & 5 & 6 & 7\end{array}$

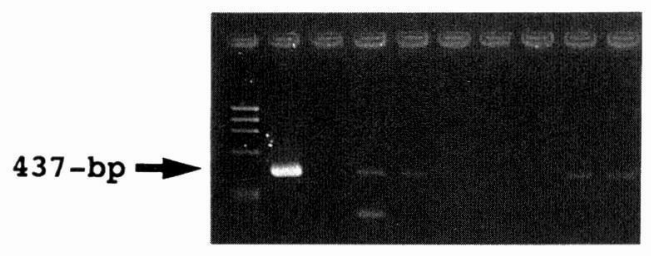

Fig. 2. Detection of Chlamydia pneumoniae DNA by capillary PCR and gel electrophoresis.

M: molecular weight markers; P: positive control (C. pneumoniae TW-183); N: negative control; lane 1-7: clinical specimens.

The expected PCR products (437-bp) are visible in lanes 1, 2, 6 and 7 . ucts were subjected to $2 \%$ agarose gel electrophoresis, were observed under UV at $260 \mathrm{~nm}$ and were photographed after staining with ethidium bromide (Fig. 2). Culture: For the culture of C.pneumoniae, the nasopharyngeal specimen obtained with the Dacron swab (DAKO DIAGNOSTICS LTD., USA) was immediately placed in $1 \mathrm{ml}$ of SPG with $10 \%$ fetal bovine serum (FBS) at $4{ }^{\circ} \mathrm{C}$ for $1-4$ hs and stored at $-70{ }^{\circ} \mathrm{C}$. Twenty specimens that showed high antibody titers on serological study were subsequently shipped to Dr. Hammerschlag at the State University of New York Health Science Center. During transport they were frozen at $-20{ }^{\circ} \mathrm{C}$ in dry ice. Cultures were performed by inoculating $200 \mu \mathrm{l}$ of each specimen in cycloheximide-treated HEp-2 cells grown in 96-well microtiter plates (Roblin et al. 1992). All specimens were passaged once, and isolates were identified as chlamydiae with fluoresceinconjugated antibody to the lipopolysaccharide genus antigen (Pathfinder Chlamydia Culture Confirmation System; Kallestad Diagnostic, Chaska, Minn, USA). Identification was confirmed with a $C$. pneumoniae-specific monoclonal antibody (Washington Research Foundation, Seattle). Isolates were also stained by antimajor outer membrane protein and $C$. trachomatis-specific monoclonal antisera (Syva, Palo Alto, Calif, USA) to identify C. trachomatis.

Enzyme antibody technique: The IDEIA Chlamydia (DAKO DIAGNOSTIC LTD., USA) kit (IDEIA) was used. After reaction according to the manufacture's instructions, absorbance at $486 \mathrm{~nm}$ was determined with ELISA ANALYZER ETY96 (Toyosokki Co., Ltd., Tokyo, Japan). Statistical analysis: A chi-square analysis 
was used to determine statistical significance.

\section{Results}

Incidence of C.pneumoniae infection in pediatric patients with lower respiratory tract infection

The incidence of $C$. pneumoniae antibodies and/or antigen according to age in 130 patients with lower respiratory

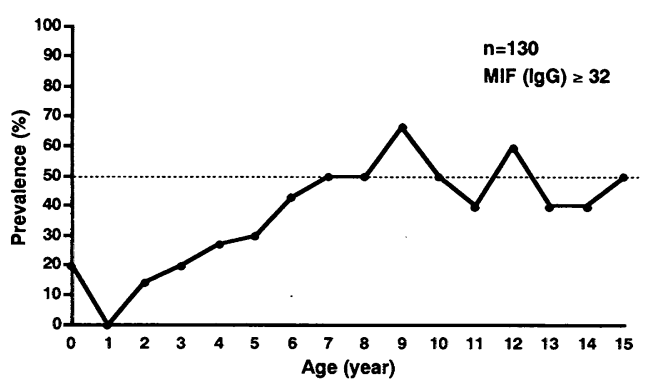

Fig. 3. Prevalence rate to C. pneumoniae according to age in 130 patients with lower respiratory tract infection. tract infection is shown in Fig. 3. The rate was $20 \%$ in 0 -year-old patients and $0 \%$ in 1 -year-old patients. The rate gradually increased in patients aged 2 years or over, reaching $42.9 \%$ in 6-year-old patients. In patients over 6 years of age, the rate remained at approximately $50 \%$. Ten patients were diagnosed by serological testing using MIF test and positive for either PCR or culture methods for isolating C.pneumoniae in the 130 patients. The 10 patients were 4 (4.4\%) of the 91 patients with pneumonia and 6 (15.4\%) of the 39 patients with bronchitis.

Mycoplasma pneumoniae was responsible for lower respiratory infection in $22(16.9 \%)$ of 130 patients; in $16(17.6 \%)$ of 91 pneumonia patients and in 6 (15.4\%) of 39 bronchitis patients. Other possible etiologic pathogens for lower respiratory tract infections were not tested.

The characteristics of 10 patients due to C.pneumoniae, 7 boys and 3 girls, are shown in Table 1 . The age ranged

TABLE 1.

Characteristics of 10 patients with Chlamydia pneumoniae lower respiratory tract infection

\begin{tabular}{|c|c|c|c|c|c|c|c|c|c|c|c|c|c|}
\hline case & sex & age & disease & PCR & culture & IDEIA & IgM & $\begin{array}{l}\text { IgG } \\
(\mathrm{A})\end{array}$ & $\begin{array}{l}\text { IgG } \\
\text { (C) }\end{array}$ & $\begin{array}{l}\text { WBC } \\
(/ \mu 1)\end{array}$ & $\begin{array}{c}\text { CRP } \\
\text { (mg/dl) }\end{array}$ & $\begin{array}{c}\mathrm{ESR} \\
(\mathrm{mm} / \mathrm{h})\end{array}$ & CA \\
\hline 1 & $\mathrm{~F}$ & $9 m$ & Bron & + & - & + & 16 & 64 & 256 & 11,400 & 0.2 & 3 & 512 \\
\hline 2 & F & $2 \mathrm{y} 1 \mathrm{~m}$ & Bron & + & - & - & 32 & $<8$ & 128 & 8,900 & 0.1 & 24 & 32 \\
\hline 3 & M & $3 y 1 m$ & Pneu & + & - & - & 64 & $<8$ & 128 & 17,800 & 1.0 & 51 & 256 \\
\hline 4 & $\mathrm{~F}$ & $3 \mathrm{y} 9 \mathrm{~m}$ & Pneu & + & - & - & $<8$ & 32 & 512 & 9,000 & 2.7 & 50 & 512 \\
\hline 5 & M & $4 y 8 m$ & Bron & + & - & - & $<8$ & 32 & 128 & 6,300 & 0.4 & 4 & 128 \\
\hline 6 & M & $5 y 6 m$ & Bron & + & - & - & $<8$ & 32 & 128 & 7,100 & 0.2 & N.D. & 16 \\
\hline 7 & M & $5 \mathrm{y} 8 \mathrm{~m}$ & Pneu & + & - & - & 16 & 64 & 256 & 10,300 & 3.5 & 55 & 512 \\
\hline 8 & M & $5 y 1 \mathrm{~m}$ & Bron & + & - & - & $<8$ & 256 & 512 & 6,900 & 0.2 & 33 & 16 \\
\hline 9 & M & $9 y 5 m$ & Bron & + & - & - & $<8$ & 1,024 & 1,024 & 8,600 & 0.2 & 23 & 512 \\
\hline 10 & M & $12 \mathrm{y} 4 \mathrm{~m}$ & Pneu & N.D. & + & - & $<8$ & 1,024 & 1,024 & 7,800 & 0.3 & 5 & 32 \\
\hline
\end{tabular}

Bron: acute bronchitis; Pneu: pneumonia; PCR: polymerase chain reaction; +: positive; -: negative; N.D.: not done; IgM: C.pneumoniae IgM; IgG (A): C.pneumoniae IgG (acute); IgG (C): C.pneumoniae IgG (convalescent); CA: cold agglutination test 
from 9 months to 12 years old and half of them were under 5 years old. $C$. pneumoniae was detected by PCR in all 9 examined cases. One case who was not examined by PCR was positive by culture method. Only one case of 10 examined was positive by IDEIA. In laboratory tests, there were few cases who showed leukocytosis and positive C-reactive protein (CRP), but the erythrocyte sedimentation rate (ESR) was elevated in 6 cases. The cold agglutination test was elevated in 6 cases, of whom 4 cases showed high titer $(2512)$. As for serum antibodies to C.pneumoniae, 4 cases were positive for IgM antibody in acute sera with the range of $16-64$. IgG antibody in these 10 cases ranged from
128 to 1,024 .

The clinical symptoms of 10 patients is shown in Table 2. There were 4 cases of pneumonia. One of them was thought to be a mixed infection with Mycoplasma pneumoniae diagnosed serologically. The remaining 6 cases were bronchitis. One patient with pneumonia had to be admitted to the hospital. Cough was observed as one of the initial symptoms in all 10 patients and 8 had productive coughs. Nine were afebrile or had febricula. The remaining patient had fever greater than $38^{\circ} \mathrm{C}$. Rales were heard in 6 on auscultation. Other symptoms were post-nasal discharge that persisted for a long period (4-8 weeks) in 4 and hoarseness in 3 patients. Sinusitis was

TABLE 2

Clinical symptoms of 10 patients with Chlamydia pneumoniae lower respiratory tract infection

\begin{tabular}{|c|c|c|c|c|c|}
\hline & & n (\%) & & & n (\%) \\
\hline 1) & Sex & & 6) & Auscultation & \\
\hline & Male & $7(70)$ & & Rale & $6(60)$ \\
\hline & Female & $3(30)$ & & (Wheezing) & $3(30)$ \\
\hline 2) & Age (9 months to 12 years) & & 7) & Other symptoms & \\
\hline & $<5$ years & $5(50)$ & & Post-nasal discharge & $4(40)$ \\
\hline & 25 years & $5(50)$ & & Hoarseness & $3(30)$ \\
\hline 3) & Diagnosis & & & Pharyngalgia & $2(20)$ \\
\hline & Bronchitis & $6(60)$ & & Lymph-nodes swelling & $1(10)$ \\
\hline & *Pneumonia & $4(40)$ & & Chest pain & $1(10)$ \\
\hline 4) & Admission & & 8) & Complications & \\
\hline & No & $9(90)$ & & Sinusitis & $2(20)$ \\
\hline & Yes & $1(10)$ & & Conjunctivitis & $2(20)$ \\
\hline 5) & Initial symptoms & & & Otitis media & $1(10)$ \\
\hline & Productive cough & $8(80)$ & & Iritis & $1(10)$ \\
\hline & Non-productive cough & $2(20)$ & 9) & Period of visiting clinics after onset & \\
\hline & Nasal discharge (obstruction) & $6(60)$ & & $<1$ week & $5(50)$ \\
\hline & Fever $\left(>37^{\circ} \mathrm{C}\right)$ & $5(50)$ & & $<1$ month & $3(30)$ \\
\hline & Fever $\left(\geq 38^{\circ} \mathrm{C}\right)$ & $1(10)$ & & 21 month & $2(20)$ \\
\hline & Joint, Muscle pain & $1(10)$ & & & \\
\hline & Ophthalmalgia & $1(10)$ & & & \\
\hline
\end{tabular}

*One was a mixed infection with Mycoplasma pneumoniae. 
observed in 2 of 4 patients who had postnasal discharge.

The chest radiograph of a 12-year-old boy (case 10) with C.pneumoniae pneumonia is shown in Fig. 4. He suffered

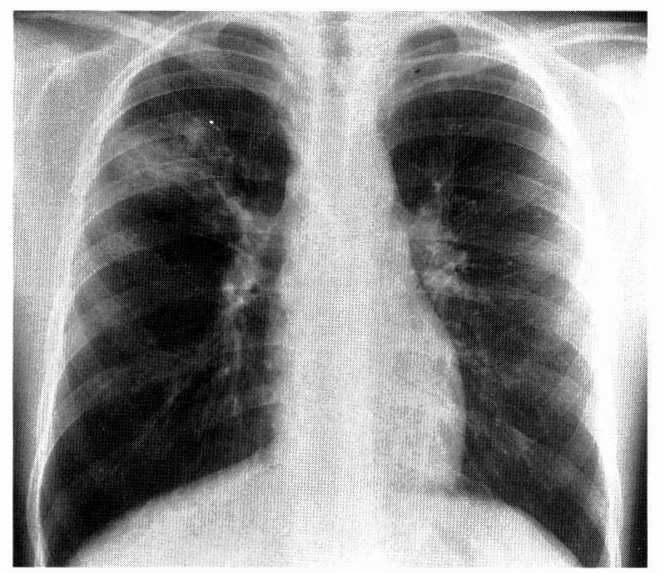

Fig. 4. Chest radiograph of a 12-year-old boy with pneumonia by C.pneumoniae demonstrating a poorly demarcated infiltration in the right upper lobe. from productive cough without fever. He was admitted to the Department of Plastic Surgery to be operated for baldness. Chest radiograph for the preoperative examination revealed a shadow in the right upper lung field. Under the diagnosis of pneumonia he was referred to our department for further evaluations. He complained of productive cough, slight hoarseness and pharyngalgia. His pharynx was slightly injected and wheezing was heard on auscultation. The serum IgG antibody titer for $C$. pneumoniae was high at 1,024 in the acute phase, however IgM antibody titer was negative. C.pneumoniae was isolated from the pharynx by culture.

Intrafamilial infection of C.pneumoniae was observed in 2 families (Fig. 5). Three weeks after the patient (case 3) started coughing, his older brother (case 6 ) and younger sister (case 1) developed similar coughs. Both children were diagnosed as C.pneumoniae infection by PCR of the pharyngeal swab and serum

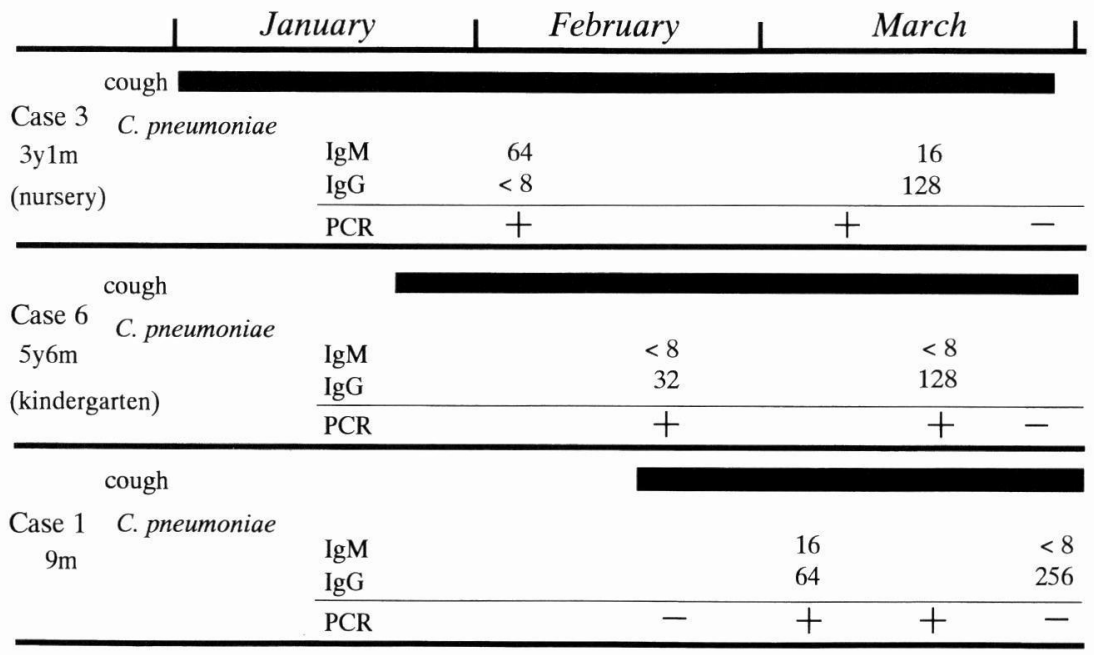

Fig. 5. A case of familial infection with Chlamydia pneumoniae. 
TABLE 3.

Incidence of seropositivity to Chlamydia pneumoniae according to age and sex in healthy children

\begin{tabular}{|c|c|c|c|c|c|c|}
\hline \multirow{2}{*}{$\begin{array}{c}\text { Age } \\
\text { (year) }\end{array}$} & \multicolumn{3}{|c|}{ no. of samples } & \multicolumn{3}{|c|}{ no. of positive (\%) } \\
\hline & $\sigma^{\lambda}$ & 우 & total & $\delta$ & 우 & total \\
\hline Cord blood & & & 30 & \multicolumn{2}{|c|}{$15(50)$} & $15(50)$ \\
\hline$\leq 6 \mathrm{Mo}$ & 10 & 4 & 14 & $1(10)$ & $1(25)$ & $2(14)$ \\
\hline $7 \mathrm{Mo} \sim 1$ & 6 & 6 & 12 & $0(0)$ & $1(17)$ & $1(8)$ \\
\hline 1 & 10 & 10 & 20 & $0(0)$ & $0(0)$ & $0(0)$ \\
\hline 2 & 10 & 10 & 20 & $2(20)$ & $1(10)$ & $3(15)$ \\
\hline 3 & 23 & 15 & 38 & $0(0)$ & $2(13)$ & $2(5)$ \\
\hline 4 & 40 & 27 & 67 & $4(10)$ & $5(19)$ & $9(13)$ \\
\hline 5 & 45 & 41 & 86 & $8(18)$ & $3(7)$ & $11(13)$ \\
\hline 6 & 20 & 24 & 44 & $5(25)$ & $6(25)$ & $11(25)$ \\
\hline 7 & 7 & 13 & 20 & $4(57)$ & $7(54)$ & $11(55)$ \\
\hline 8 & 8 & 21 & 29 & $6(75)$ & $7(33)$ & $13(45)$ \\
\hline 9 & 9 & 17 & 26 & $4(44)$ & $7(41)$ & $11(42)$ \\
\hline 10 & 11 & 19 & 30 & $5(46)$ & $10(53)$ & $15(50)$ \\
\hline 11 & 12 & 17 & 29 & $6(50)$ & $7(41)$ & $13(45)$ \\
\hline 12 & 17 & 23 & 40 & $7(41)$ & $9(39)$ & $16(40)$ \\
\hline 13 & 8 & 17 & 25 & $3(38)$ & $8(47)$ & $11(44)$ \\
\hline 14 & 11 & 14 & 25 & $5(46)$ & $6(43)$ & $11(44)$ \\
\hline 15 & 13 & 12 & 25 & $5(39)$ & $6(50)$ & $11(44)$ \\
\hline Total & 260 & 290 & 550 & $65(25)$ & $86(30)$ & $151(27)$ \\
\hline
\end{tabular}

antibody titers. The pharyngeal swab in the sister was also positive for IDEIA.

Incidence of serum antibodies against C.pneumoniae according to age in healthy children

Table 3 shows the incidence of seropositivity for C.pneumoniae according to age and sex. The umbilical cord blood samples from 15 (50\%) of the 30 cases showed IgG antibodies. Thereafter the incidence gradually decreased and was $0 \%$ in the 1-year-old children. The incidence stayed at this low level in the children aged under 5 years but increased rapidly in those older than 6 years. More than half of the 7-year-old children (11/20 or $55 \%)$ possessed the antibodies.
There was no change in the incidence, approximately $40-50 \%$, in children over 7 years of age (Fig. 6). There was no sexual difference in serum antibody incidence (Fig. 7).

There was no significant difference in the incidence according to age between the patients and the healthy children.

The incidence for C.trachomatis was $30 \%$ in the umbilical cord blood samples, but thereafter, in childhood, the incidence decreased.

The incidence for C.psittaci was also low, $0.86 \%$ (5/580), in all ages.

An IgG antibody titer of 2512 , which has been regarded as indicating recent infection, was observed in 13 (2.2\%) of the 580 subjects (including 30 cord blood 


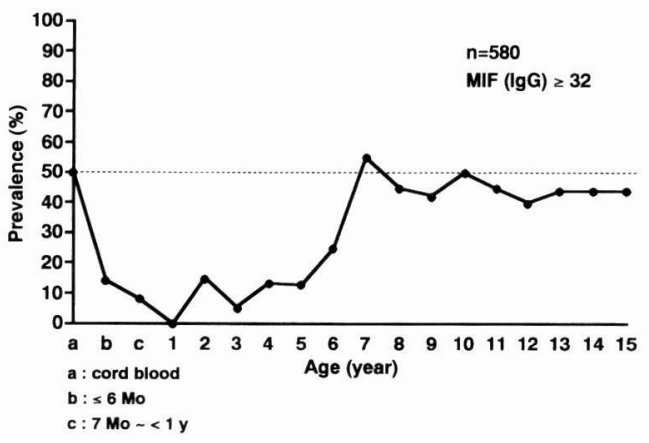

Fig. 6. Prevalence rate to C.pneumoniae according to age in healthy children.

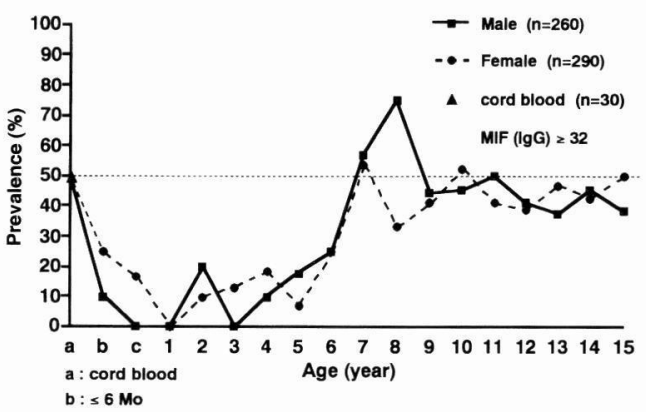

Fig. 7. Prevalence rate to C.pneumoniae according to age and sex in healthy children.

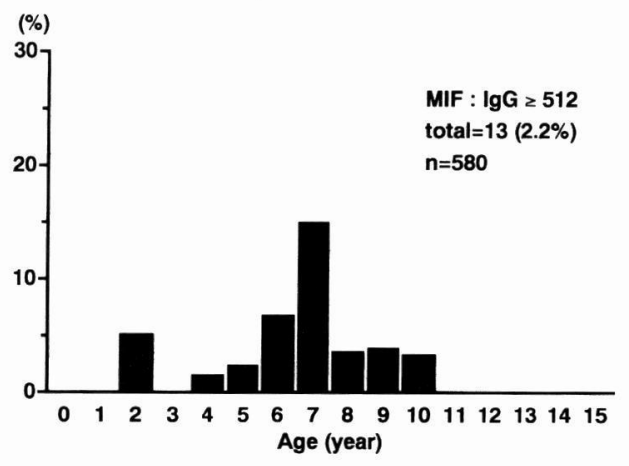

Fig. 8. Age distribution of cases with high C.pneumoniae antibody titer determined by MIF test. samples). Their ages ranged from 2 to 10 years (Fig. 8). The medical history for the previous 3 months in 8 of 13 children was taken. Six of the 8 children had recently been brought to private clinics because of cough, nasal discharge and febricula. None of them had to be admitted to the hospital under a diagnosis of pneumonia or bronchitis and two children had no symptoms.

\section{Discussion}

C. pneumoniae, the new third species of Chlamydia passed from human to human, was given this name by Grayston et al. (1989). Recent surveys in Europe and the United States have found that the serum of over $50 \%$ of adults have IgG antibodies to C.pneumoniae as determined by the MIF test, suggesting that infection by C.pneumoniae is common and frequently subclinical (Freidank et al. 1993; Kern et al. 1993). In these studies in Western countries there have been only a few reports on the infection in children. Surveys of the incidence of C.pneumoniae infection according to age in Denmark and in Seattle showed that the rate was low in infants, increased rapidly in teenagers, and continued to increase until middle age. Saikku et al. (1988) determined the C.pneumoniae antibody titer in 220 children with acute lower respiratory tract infection who were under 5 years of age, in the Philippines, and reported that positivity increased with age: the serum was positive in $31 \%$ of 4 -year-old children. In this age group 14 children (6.4\%) showed an antibody titer indicating acute infection. The investigators assumed that the 
initial infection with C.pneumoniae occurs at a younger age in the tropics than in Northern Europe. In Japan, Kishimoto (1990) investigated the incidence of C.pneumoniae antibodies according to age and reported that the incidence increased more rapidly in children aged 6 years or over in comparison with Western countries and reached a value of at least $60 \%$ in children aged under 15 years. However, Kishimoto's method of determining the antibody titer to C.pneumoniae might have been inaccurate due to cross-reactivity with $C$. trachomatis or C.psittaci, because they used the microplate immunofluorescence antibody technique (MFA) which uses inclusion bodies containing reticulate body (RB) as the antigen. The MIF test we employed, which uses individual $\mathrm{EB}$ as the antigen, is the most reliable for the determination of specific antibody titers to various species of Chlamydia. Ouchi et al. (1991) investigated the incidence of individual antibodies according to age in Japan by using three specific types of EB of Chlamydia as antigens. Ouchi et al. determined the incidence of antibodies for each species of Chlamydia by MIF test in cord blood samples, sera from patients aged 7 months or over who had been brought to hospital, and sera from healthy adults. The study showed that the incidence of the C.pneumoniae antibodies increased rapidly in 4- to 7-yearold children, and that $44 \%$ of the 8 - to 11 year-old children already possessed the antibody. The incidence was approximately $50 \%$ in the age group over 12 years. Data in healthy children have not been reported.

In the present study, we determined the antibody titer for C.pneumoniae and other Chlamydia species (C.trachomatis and C.psittaci) by MIF test in 30 umbilical cord blood samples and in sera from 550 healthy children. We also investigated changes in the incidence of antibodies according to age. We also assessed the presence of antigen by culture or PCR method and determined antibody titers in paired sera by MIF test in pediatric patients with lower respiratory tract infection.

The survey of the C.pneumoniae incidence according to age in healthy children revealed that $50 \%$ of the cord blood samples had IgG antibodies. None of the samples showed elevated IgM antibody or an IgG titer $z 512$. The incidence decreased and reached $0 \%$ in the oneyear-old children. The changes in IgG antibody titer in early infancy can be attributed to the transient presence of antibodies of maternal origin. The incidence remained low in children aged under 5 years, but increased rapidly in children aged over 6 years, reaching $55 \%$ in 7-year-old children. The incidence was $40-50 \%$ in children aged over 7 years, showing no change with age. The present results differ from the results of the surveys in Seattle and Denmark (Grayston et al. 1990) in which the incidence was elevated in younger children. In contrast, Wang and Grayston (1986) reported that the incidence in childhood in Taiwan was $41 \%$. C.pneumoniae might be considered to have a higher rate of invasion in Asia than in Western countries. Because the population density in Asia is much higher than in Western countries, Saikku et al. (1988) proposed that the incidence may be related to population density.

Regarding the high antibody titers to 
C.pneumoniae in healthy children in our study, C.pneumoniae infection is likely to produce mild symptoms like common cold or to be subclinical in most cases.

The incidence of C.pneumoniae in pediatric lower respiratory tract infection was $7.7 \%$ (10/130), while the incidence of respiratory tract infection by Mycoplasma pneumoniae was $16.9 \%(22 / 130)$. The frequency of involvement of C.pneumoniae in bronchitis was the same as that of Mycoplasma pneumoniae.

C.pneumoniae outbreaks were observed in group living conditions (Saikku et al. 1985; Kleemola et al. 1988; Grayston et al. 1989) and in Japan, familial infection has been reported by Yamazaki et al. (1990). The incubation period of a $C$. pneumoniae infection is thought to be approximately 3 weeks (Grayston, 1994) and the same interval was observed in our intrafamilial infections.

As for clinical manifestations, Grayston et al. (1990) reported that pharyngalgia was frequently present in C.pneumoniae infection with low incidence of fever and significantly high incidence of hoarseness. Hospital visits were delayed because of the mild initial symptoms. Thom and Grayston (1991) reported that sinus tenderness on percussion was observed in $36 \%$ of $C$. pneumoniae infection and about $5 \%$ of them had sinusitis. Soejima et al. (1994), investigating adult patients with $C$. pneumoniae pneumonia, reported that the incidence of non-productive cough was high. Prolonged cough, hoarseness and post-nasal discharge are considered characteristic in previous reports and this study. It is difficult to diagnose $C$. pneumoniae infection by only clinical symptoms.
According to the serological diagnosis by MIF test, IgM antibody appeared about 3 weeks after the onset of symptoms and IgG was elevated 6-8 weeks after the onset. IgM hardly appeared in reinfection and IgG titer became high 1-2 weeks after the onset of symptoms (Grayston et al. 1986). In the present study IgG antibody titer was greater than 512 in 4 of 10 patients. Four patients were thought to be initial infection as the IgG antibody titer remained at a maximum 256 even in the convalescence stage.

In cultures, the organism was isolated in only one of our 10 patients. HL cells have been considered highly sensitive as culture cells for initial isolation of $C$. pneumoniae (Cles and Stamm, 1990), but Hep-2 cells have been commonly used in cultures since Roblin et al. (1992) reported that Hep-2 cells are more sensitive than HL cells. However, the actual isolation is not easy and attempts to isolate C.pneumoniae from many patients in whom infection was strongly suspected have been successful in only a limited number of institutions. Probably because during the long time period between specimen collection and the start of culture, C.pneumoniae might have been inactivated, or because of the low number of $C$. pneumoniae itself. Kuo et al. (1988) reported that C.pneumoniae is inactivated by acute storage at $-70{ }^{\circ} \mathrm{C}$ in SPG buffer after specimen collection and is rapidly inactivated even at room temperature. For the time being, it is considered to be important that C.pneumoniae should be stored at $4{ }^{\circ} \mathrm{C}$ for $1-4$ hs soon after specimen collection and subsequently frozen at $-70{ }^{\circ} \mathrm{C}$. Roblin et al. (1992) recommended the addition of $10 \%$ FBS to the SPG buffers and nasophar- 
ynx specimens in throat swabs.

Capillary PCR, which was performed in the present study, is 1,000 times more sensitive than conventional PCR in the detection of C.pneumoniae DNA (Kawayama, 1993). Furthermore it takes only a short time, about $30 \mathrm{~min}$, for the reaction. C.pneumoniae-specific DNA was detected by this technique in all patients in whom cultures were successful except one.

IDEIA, originally used for the detection of C.trachomatis antigen and $C$. pneumoniae antigen, can be used although there is a difference in sensitivity between the two species (Kanamoto, 1992). Only one patient was positive in our 10 patients. However, the amount of antigen in the specimens tested might have been small. The kit is therefore of limited usefulness for general screening.

The present study revealed that $C$. pneumoniae infection is common in Japan not only in adults but also in children. The organism has recently been reported as a cause of ischemic heart disease, and in fact, some reports describe its isolation from the coronary artery lesion (Kuo et al. 1993). In addition, we found a boy with iritis due to C.pneumoniae (Yamada et al. 1994). Thus C.pneumoniae infections present a various degree of correlation with certain diseases. Further clinical investigations would be required to establish the incidence of C. pneumoniae infections in childhood.

Acknowledgments: The author is grateful to Prof. Hirohisa Kato for giving the opportunity to perform this study and for his guidance and suggestions. The author also thanks Dr. Takashi Motohiro and Dr. Yasutaka Sakata for their direct guidance, Drs. Keiko
Oda, Naoki Tsumura, and various doctors of Kita-2 Laboratory, Ms. Sumiko Nakashima and Ms. Kumiko Morita, and Dr. Yasuo Kanamoto of the Division of Microbiology, Hiroshima Prefectural Institute of Public Health, for valuable research data, Dr. Kazunobu Ouchi, Department of Pediatrics, Saiseikai Shimonoseki General Hospital for direct guidance on MIF procedures, Prof. Margaret R. Hammerschlag and Ms. Patricia M. Roblin, Division of Infectious Diseases, Department of Pediatrics, SUNY Health Science Center, Brooklyn, New York, for their help with cultures, and various doctors of the affiliated hospitals for their cooperation in collecting serum samples.

\section{References}

Campbell, L.A., Melgosa, M.P., Hamilton, D.J., Kuo, C.C. and Grayston, J.T. (1992). Detection of Chlamydia pneumoniae by polymerase chain reaction. J. Clin. Microbiol. 30, 434-439.

Chirgwin, K., Roblin, P.M., Geluing, M., Hammerschlag, M.R. and Schachter, J. (1991). Infection with Chlamydia pneumoniae in Brooklyn. J. Infect. Dis. 163, 757-761.

Cles, L.D. and Stamm, W.E. (1990). Use of HL cells for improved isolation and passage of Chlamydia pneumoniae. J. Clin. Microbiol. 28, 938-940.

Freidnak, H.M. and Braula, D. (1993). Prevalence of antibodies to Chlamydia pneumoniae TWAR in a group of German medical students. J. Infect. 27, 89-93.

Grayston, J.T. (1994). Chlamydia pneumoniae (TWAR) infections in children. Pediatr. Infect. Dis. J. 13, 675-684.

Grayston, J.T., Campbell, L.A., Kuo, C.C., Mordhorst, C.H., SAIKKU, P. et al. (1990). A new respiratory tract pathogen: Chlamydia pneumoniae strain TWAR. J. Infect. Dis. 161, 618625.

Grayston, J.T., Kuo, C.C., Campbell, L.A. and WANG, S.P. (1989). Chlamydia pneumoniae sp. nov. for Chlamydia sp. strain TWAR. Int. 
J. Syst. Bacteriol. 39, 88-90.

Grayston, J.T., Kuo, C.C., Wang, S.P. and Altman, J. (1986). A new Chlamydia psittaci strain, TWAR, isolated in acute respiratory tract infections. N. Engl. J. Med. 315, 161-168.

Grayston, J.T., Mordhorst, C., Bruu, A.L., Vene, S. and WANG, S.P. (1989). Countrywide epidemics of Chlamydia pneumoniae, strain TWAR, in Scandinavia, 1981-1983. J. Infect. Dis. 159, 1111-1114.

Grayston, J.T., WANG, S.P., Kuo, C.C. and CAMPBell, L.A. (1989). Current knowledge on Chlamydia pneumoniae, strain TWAR, an important cause of pneumonia and other acute respiratory diseases. Eur. J. Clin. Microbiol. Infect. Dis. 8, 191-202.

Каламото, Y. (1992). Evaluation of IDEIA Chlamydia test for detection of Chlamydia pneumoniae in respiratory infection. Prog. Med. 12, 983-986. (in Japanese)

Kanamoto, Y. and SaKano, T. (1992). Isolation of Chlamydia pneumoniae from a patient with acute bronchitis. J. Jpn. Associ. Infect. Dis. 66, 637-642. (in Japanese)

KAWAYAMA, T. (1993). Evaluation of capillary polymerase chain reaction for detection of Chlamydia pneumoniae. J. Kurume Med. Associ. 56, 1075-1083. (in Japanese)

Kern, D.G., NeL, M.A. and SchaChTER, J. (1993). A seroepidemiologic study of Chlamydia pneumoniae in Rhode Island. Chest 104, 208-213.

Кisнiмото, T. (1990). Studies on Chlamydia pneumoniae, strain TWAR, infection 2. Seroepidemiology of TWAR on healthy controls and patients with acute respiratory infections. J. Jpn. Associ. Infect. Dis. 64, 986993. (in Japanese)

KLEEMola, M., SAIKKU, P., Visakorpi, R., Wang, S.P. and Grayston, J.T. (1988). Epidemics of pneumonia caused by TWAR, a new Chlamydia organism, in military trainees in Finland. J. Infect. Dis. 157, 230-236.

Kuo, C.C. and Grayston, J.T. (1988). Factors affecting viability and growth in Hela 229 cells of Chlamydia sp. strain TWAR. J. Clin. Microbiol. 26, 812-815.

Kuo,C.C., Shor, A., Campbell, L.A., Fukushi, H., Patton, D.L. et al. (1993). Demonstration of
Chlamydia pneumoniae in atherosclerotic lesion of coronary arteries. J. Infect. Dis. 167, 841-849.

MarRie, T.J., Grayston, J.T., Wang, S.P. and Kuo, C.C. (1987). Pneumonia associated with the TWAR strain of Chlamydia. Ann. Intern. Med. 106, 507-511.

Ouchi, K., Каламото, Y. and Ushio, M. (1991). Prevalence of antibodies to Chlamydia pneumoniae (strain TWAR) and other Chlamydia in Japan. J. Jpn. Associ. Infect. Dis. 65, 19-25. (in Japanese)

Roblin, P.M., Dumornay, W. and Hammerschlag, M.R. (1992). Use of HEp-2 cells for improved isolation and passage of Chlamydia pneumoniae. J. Clin. Microbiol. 30, 1968-1971.

Saikku, P., Ruutu, P., Leinonen, M., Paneluus, J., TuPASI, T.E. et al. (1988). Acute lower-respiratory-tract infection associated with Chlamydial TWAR antibody in Filipino children. J. Infect. Dis. 158, 1095-1097.

SaIkku, P., Wang, S.P., Kleemola, M., Brander, E., Rusanen, E. et al. (1985). An epidemic of mild pneumonia due to an unusual strain of Chlamydia psittaci. J. Infect. Dis. 151, 832839.

Soeлma, R., Kishimoto, T., KimuRA, M. and Miyashita, N. (1994). Respiratory infection; Chlamydia pneumoniae pneumonia. Antibiotics and Chemotherapy 10, 55-60. (in Japanese)

Thom, D.H. and Grayston, J.T. (1991). Infections with Chlamydia pneumoniae strain TWAR. Clinics in Chest Medicine 12, 245-256.

WANG, S.P. and GraYston, J.T. (1970). Immunologic relationship between genital TRIC, lymphogranuloma venereum, and related organisms in a new microtiter indirect immunofluorescence test. Am. J. Ophthalmol. 70, 367-374.

WANG, S.P. and Grayston, J.T. (1986). Microimmunofluorescence serological studies with the TWAR organism. In Chlamydial infections, ed. Oriel, J. D., Ridway, G., Schachter, J., Taylor-Robinson, D. and Ward, M., pp. 329332. New York: Cambridge University Press.

Yamada, S., Tsumura, N., Nagai, K., Yamada, T., SAKATA, Y. et al. (1994). A child with iritis due 
to Chlamydia pneumoniae infection. J. Jpn. Associ. Infect. Dis. 68, 1543-1547. (in Japanese)

Yamazaki, T., Nakada, H., Sakura, N., Kuo, C.C.,
WANG, S.P. et al. (1990). Transmission of Chlamydia pneumoniae in young children in a Japanese family. J. Infect. Dis. 162, 13901392. 